\title{
BMJ Open Supporting the provision of palliative care in the home environment: a proof-of-concept single-arm trial of a PalliativE Carers Education Package (PrECEPt)
}

\author{
Liz Forbat, ${ }^{1}$ Erna Haraldsdottir, ${ }^{2}$ Marsha Lewis, ${ }^{3}$ Ken Hepburn ${ }^{4}$
}

To cite: Forbat $L$, Haraldsdottir E, Lewis M, et al. Supporting the provision of palliative care in the home environment: a proof-of-concept single-arm trial of a PalliativE Carers Education

Package (PrECEPt). BMJ Open 2016:6:e012681. doi:10.1136/bmjopen-2016012681

- Prepublication history for this paper is available online. To view these files please visit the journal online (http://dx.doi.org/10.1136/ bmjopen-2016-012681).

Received 18 May 2016 Revised 19 July 2016 Accepted 28 September 2016

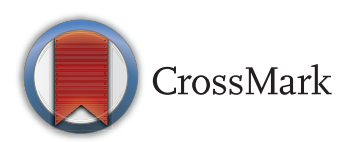

For numbered affiliations see end of article.

Correspondence to Professor Liz Forbat; elizabeth.forbat@acu.edu.au

\begin{abstract}
Introduction: Practical educational interventions for palliative carers are needed. Current supports frequently rely on carers travelling to a central venue to receive education. A substantial gap therefore exists around determining how high-quality relevant information can be delivered nationally, with limited cost implications, using educational methods that are acceptable to carers in palliative care. This study seeks to design and assess feasibility and acceptability of a distance-learning approach to educating carers.
\end{abstract}

Methods: This is an embedded mixed-method feasibility and acceptability study. It embeds an unblinded 1-arm pilot test, with subsequent qualitative interviews which will be used to inform the assessment of the intervention's acceptability and feasibility. The theoretical framework is self-efficacy theory, whereby we seek to impact carers' beliefs in their ability to carry out and succeed in caring tasks and situations. The educational materials focused on pain and nutrition/hydration will be developed in phase 1 with former carers $(n=8)$ providing input into the content and style of materials. The educational package privileges adult-learning styles, recognising and responding to the learner's context including their learning needs, prior knowledge and motivations for engaging in education. The materials will be tested with up to 24 current carers.

Analysis: Analysis will focus on determining recruitment processes for a full-scale study, data collection procedures/completion rates, queries directed to the hospice from carers involved in the feasibility work, mode of delivery and content of the materials. The primary outcome measure is self-efficacy, with other measures focused on caregiver preparedness and caregiving tasks, consequences and needs questionnaire. Adherence to educational components will also be collected and reported.

Ethics and dissemination: Ethical approval has been provided by the participating site, Calvary Healthcare, Canberra, reference 02-2016, and the Australian Catholic University. Results will be published

\section{Strengths and limitations of this study}

- The study addresses a key gap in the current evidence regarding how to provide support to carers.

- The pedagogical approach is explicitly articulated, which is a feature lacking in all other carer educational interventions which rely solely on describing mode and content of delivery.

- The design is single-arm proof-of-concept rather than a randomised controlled trial, reflecting the developmental stage of evolving interventions for carers in palliative care.

- To reduce burden on participants, only four outcome measures will be trialled, reducing the potential to identify other core modifiable constructs impacted by the intervention.

in peer-reviewed journals, presented at conferences and a lay summary sent to participants.

Trial registration number: ACTRN12616000601437; Pre-results.

\section{INTRODUCTION}

Families are viewed as a unit of care in palliative services. ${ }^{1}$ Informal carers' needs therefore should be identified and addressed as part of routine service provision. Carer resources and support, over and above patient diagnosis and symptom burden, predict carer burden and other carer outcomes. ${ }^{2}$ With policy and practice emphasis on home-based care and home as the preferred place of death, ensuring appropriate and adequate support for carers is critical. Such approaches need to be cognisant of carer need for knowledge, recognition of their emotional experience and the role they can play in supporting the patient. ${ }^{3}$ Further, interventions must recognise that carers may be reluctant to ask for 
help and not self-identify as a carer. ${ }^{4}$ Unmet needs have been documented in many studies and frequently include insufficient informational and emotional supports across palliative care, ${ }^{5}{ }^{6}$ as well as for specific patient/carer groups such as around cachexia. ${ }^{7}$ Practical educational interventions for carers are needed. ${ }^{8}$

Educational interventions for carers are commonplace $;^{9-12}$ education is proven to increase skills, improve caregiving competence and address information needs. ${ }^{11}$ Interventions are more likely to impact outcomes such as knowledge and self-efficacy, ${ }^{9} 13$ and preparedness for caregiving ${ }^{11}{ }^{14}$ rather than domains such as carer coping ${ }^{15}$ or anxiety, depression or burden. ${ }^{14}$ Evidence from palliative care clearly demonstrates that one-to-one and group psychoeducation is effective in gaining support and knowledge, ${ }^{16}$ preparedness for caring, competence and having information needs met. ${ }^{11}{ }^{17}$ However, these studies have typically been small scale and rolled out only in local areas. ${ }^{15}$

A deficit of such models is that they frequently rely on carers travelling to a central venue to receive education. Studies have reported that carers decline involvement in supportive group interventions due to a desire not to leave the person they are caring for. ${ }^{16}$ As a response to these time and location concerns, a number of approaches have been tested, but not without their drawbacks. First, multimedia approaches have been adopted, for example, educational DVDs, ${ }^{18}$ and videos combined with internet-based programmes ${ }^{19-21}$ have reported positive feedback from carers and health professionals on being interesting and containing relevant content. The strength of such formats is that they can be used nationally, irrespective of the carers' proximity to a specialist service, or their ability to attend an educational class at a prescribed time. ${ }^{19}$ However, in common with many approaches to caregiver education and information support, these interventions do not expressly articulate the learning and teaching styles adopted. Additionally, distance-learning methods are used widely in healthcare professional education, for example, nurses, ${ }^{22}$ surgical trainees ${ }^{23}$ and occupational therapy. ${ }^{24}$ Yet distance learning has not been widely explored for caregivers despite some early results in the dementia field offering promising feedback. ${ }^{25}{ }^{26}$ While it is recognised that accessible, brief and easily delivered education needs to be available, ${ }^{2}$ a substantial gap remains around determining how high-quality relevant information can be delivered at a national level, with limited cost implications, using educational methods which are acceptable to carers in palliative care. This study seeks to design and assess feasibility and acceptability of a distance-learning approach to educating carers.

\section{Aim}

This study involves intervention development and an embedded proof-of-concept feasibility and acceptability study.
Specific aims are to:

1. Design an innovative distance-learning educational package (PrECEPt: PalliativE Carers Education Package). Two modules, identified as priorities in the literature will be developed.

2. Determine ideal content, learning-style preferences (eg, balance of videos/vignettes/quizzes), mode of delivery (online/printed), level of detail/complexity.

3. Determine the acceptability and feasibility of the educational package to carer and healthcare professionals.

4. To understand the processes involved in delivery of the key components of PrECEPt including recruitment processes for a full-scale study, data collection procedures/completion rates, queries directed to the hospice from carers involved in the feasibility work.

5. Determine sample size, recruitment and randomisation processes for a definitive trial.

6. Examine the impact of the intervention on carer self-efficacy.

\section{THEORETICAL FRAMEWORK}

We theorise that carer self-efficacy will increase through the provision of information, skills and confidence. The focus on self-efficacy is informed by the recognition that it is a key variable in the impact of caring, ${ }^{27}$ and consequently is a frequently measured variable in general caregiving and palliative care research. ${ }^{28}$ Education interventions ${ }^{13}$ have also determined that self-efficacy is a modifiable variable.

Self-efficacy theory refers to an individual's confidence to carry out a specific task, and the belief in one's own ability to succeed in a task or situation. ${ }^{29}$ Self-efficacy is linked with initiation and persistence of coping, and mediates the relationships between stressors and outcomes. Consequently, high self-efficacy is considered a predictor of continued caregiving, mediating the development of debilitating emotional responses such as depression, anxiety or pessimism. ${ }^{30}$ Anxiety and selfefficacy are linked, with carers reporting low self-efficacy having higher anxiety scores. ${ }^{31}$

Bandura $^{29}$ explains that expectations regarding self-efficacy are predicated on "four major sources of information: performance accomplishments, vicarious experience, verbal persuasion and physiological states" (p. 195). Consequently, this intervention will target those elements in the context of caregiving tasks and beliefs.

\section{METHODS AND ANALYSIS}

Primary research question: What is the ideal content and mode of delivery for a carer's distance education resource?

Secondary research question: Does the education package impact carer self-efficacy, or preparedness for caregiving?

\section{Design}

This is an embedded mixed-method feasibility and acceptability study. It embeds an unblinded one-arm 
pilot test, with subsequent qualitative interviews which will be used to inform the assessment of the intervention's acceptability and feasibility.

Participants in the pilot trial will receive educational resource material focused on nutrition and hydration, and pain. Carers and patients will continue to receive usual care from the community palliative care team.

The design encompasses phases i/ii of the UK's Medical Research Council (MRC) complex intervention framework. $^{32} 33$ The study is underpinned by realistic evaluation methodology, which acknowledges the complexity of interventions and the contexts in which they are delivered and assessed. ${ }^{34}$ This methodology ensures that data are gathered from a range of relevant stakeholders to identify facilitators and barriers to delivery and uptake. The aim is also to produce findings that will inform the development of a fully powered multisite trial. The study has two phases:

\section{Phase 1: intervention development (aim 1)}

PrECEPt will be developed by (1) examining the extant literature with the aim of developing education material for carers and (2) holding focus groups with eight former carers of people in receipt of palliative care. The materials will be written by palliative care nurses, a psychosocial palliative care researcher and have input from a palliative care physician. The development of materials is outlined in figure 1.

PrECEPt will consist of two units which are identified as priorities in the palliative literature on caregiver needs: pain management ${ }^{35-39}$ and nutrition/hydration needs including dietary advice, feeding techniques, hydration. ${ }^{40-42}$ The topics covered in the units and information

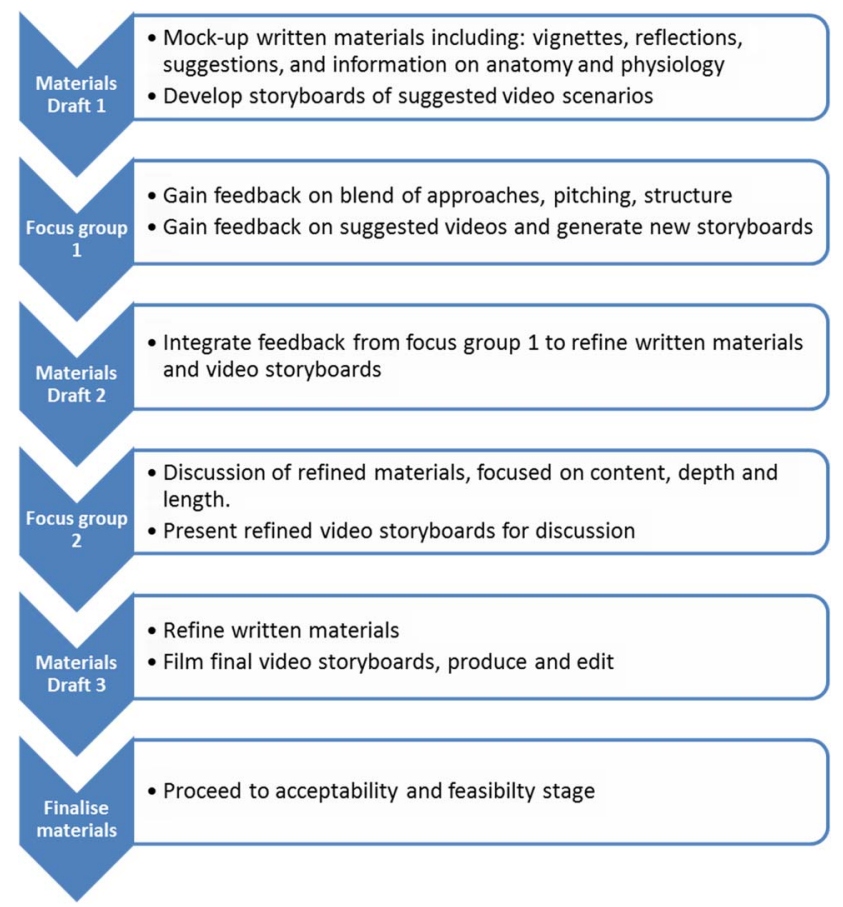

Figure 1 Intervention development process. provided will be informed by pragmatic searches of nursing (CINAHL) and medical (PubMed) databases, focusing primarily on recent relevant systematic reviews. ${ }^{43}$ The materials will be framed as information for family members, recognising the conceptual difference for carers in drawing on this policy discourse. ${ }^{44}$

The materials will be pitched at a reading level of grade $6-7$, which is the equivalent of a reading age of 11-12 years, ${ }^{45}$ using Flesch-Kinnard scores generated by Microsoft Word. The grade level is calculated on the average number of syllables per word and the average number of words per sentence. The choice of literacy level reflects educational materials of patients with cancer, building on proposed best practice. ${ }^{45} 46$

The educational package will privilege adult-learning styles, recognising and responding to the learner's context including their learning needs, prior knowledge and experience, and motivations for engaging in education. A blended approach will be adopted, incorporating didactic elements, reflexive exercises and video vignettes illustrating caregiving scenarios and potential solutions.

Distance-learning approaches will be adopted to overcome the limitations and equality disparities in offering face-to-face support to carers. Distance education is underpinned by three core elements: dialogue, structure and learner autonomy. ${ }^{47}$ Dialogue refers to the interaction between the educator's voice and the learner, which is built into the course package. In PrECEPt, dialogue is epitomised by an authorial voice which seeks to 'walk alongside' the learner and present information as if in one-to-one conversation with them. This approach intends to facilitate rapport between teacher and intended learner ${ }^{48}$ which is associated with better outcomes for learners. ${ }^{49}$ Structure refers to the variability in learners' preferences in engaging with the objectives. Autonomy relates to the control that the learner has in creating a learning plan, and how much they wish to learn and implement. ${ }^{50}$

Flexible learning also underpins the approach, with the educational package being offered to carers to use in a way that suits their circumstances, such as their preferences for amount of information, and their motivations and goals for engaging in the materials. ${ }^{51-53}$ To this end, the materials will be presented in a hierarchical fashion with core information about basic issues presented initially, progressing to increasingly complex scenarios with greater depth of explanation. Carers can then choose the level which best suits their practical situation, current knowledge base and readiness for information by moving through the materials at their own pace starting and stopping wherever fits their needs. The printed materials will be structured from basic information, through to more moderate levels of information to more sophisticated explanations of anatomy and physiology, with attendant suggestions for managing likely problems facing caregivers.

The education package will be framed around case studies of carer-patient dyads. These dyads will facilitate 
problem-based learning, which is a learner-focused pedagogical technique that allows for contextualised and applied learning. Evidence from healthcare suggests that problem-based learning offers strength in engendering clinical knowledge and skills. ${ }^{54}$ For carers, problem-based learning will be addressing key problems which are documented in the literature, for example, carers' own needs and identity. ${ }^{55}$

Consequently, PrECEPt will outline a range of presenting problems alongside activity-focused elements to encourage the reader to engage in reflection, to promote 'deep learning', that is, learning which deeply engages the individual. ${ }^{56}$ This activity approach builds on reflexive practice which is an established component of healthcare education for staff. ${ }^{57}$ In addition to prompting carers to identify their own solutions, the educational package will integrate suggestions and responses to the identified problems, drawing from evidence in the clinical literature. The materials will cover basic physiology and anatomy to explain the aetiology of symptoms, and psychoeducational elements to address the anxiety and distress which these symptoms prompt in carers. ${ }^{39} 5859$

In addition to written materials, filmed vignettes will be developed which illustrate caregiving scenarios, offering practical illustrations of problems and potential solutions. For example, a video might show a caregiver preparing a small meal, while describing his decisionmaking in what is on the plate, size of meal and how he will offer it to the person he is looking after. Videos are frequently used in distance education, and increasingly are a core mode of delivery of massive online open courses. Within PrECEPt, the films will complement the written materials, and will vary in length from 2 to $7 \mathrm{~min}$. Storyboards will be developed to outline the narrative and key learning points to be illustrated by the actors, and prompt reflection from the carers.

The development of the materials will be informed by Bandura's ${ }^{29}$ model, targeting performance accomplishments (by modelling, desensitisation, exposure and instruction), vicarious experience (through modelling in the videos and vignettes), verbal persuasion (through embedded suggestion of the ability to master tasks, and provision of instruction) and physiological states (through addressing triggers for emotional arousal, attribution errors and exposure). The materials prompt carers to discuss any queries they have with relevant healthcare professionals, but otherwise are conceptualised as stand-alone packages that do not require new or additional input from healthcare providers.

The draft educational materials will be presented to former caregivers for feedback, discussion and refinement. It is expected that several iterations of the learning resource will be required, including both written and video materials.

\section{Phase 2: feasibility study (aims 2-5)}

Up to 24 carers of people currently receiving palliative care will be invited to feasibility test PrECEPt. They will be interviewed to aid refinement of the materials and recruitment processes. To manage likely loss to follow-up, the sample size factors in over-recruitment, and seeks to achieve a final sample size of 16 carers who complete the educational materials.

Staff at the recruiting site will also be interviewed to gain feedback on recruitment processes, and the impact of the trial on interactions with the staff team (eg, capturing information on whether more/different informational queries were received). Carers will receive the educational materials by post, and be informed that the trial lasts for 6 weeks during which they can read and use the materials. At the end of 6 weeks, they will be asked to complete outcome measures, and choose if they wish to retain or return the materials.

\section{Setting, sample and recruitment}

Recruitment will proceed through a single site: the Australian Capital Territory's specialist outpatient palliative care service at Clare Holland House, Canberra, Australia. This service provides both inpatient and outpatient services to residents across the Territory, and beyond. It is staffed by a multidisciplinary team including medical, nursing, allied health, social work and pastoral care practitioners. Recruitment will proceed through the community palliative care team, who provide specialist palliative care to patients and carers where their symptoms cannot be managed by primary palliative care.

Phase 1: Eight former carers will participate in focus groups. These carers will be purposively sampled to include individuals who will be articulate about their informational and support needs, and be able to contribute to the development of the materials. Former carers were sought in order to reduce burden to current carers, and ensure recruitment did not decrease the potential pool from which phase 2 participants were drawn. Recruitment will be supported by the community palliative care team, using the following criteria:

Inclusion criteria:

I. Former carer, residing in the Australian Capital Territory;

II. Supported someone with nutrition/hydration and or pain management needs;

III. Bereaved at least 3 months previously, following guidance from Bentley and O'Connor; ${ }^{60}$

IV. Aged over 18 years and able to give informed consent;

V. No formal diagnosis of major psychiatric disorder.

Phase 2: Current informal carers, supporting someone with nutrition/hydration and or pain management issues will be invited to test PrECEPt, to determine proof-of-concept for this novel approach to carer education.

The community palliative care team will identify how many patients they have in their caseload $(n=126$ currently). All patients will be allocated a numeric code. A sample will be identified using a random number 
generator. Based on the current patient case load of 126 , an initial cohort of $20 \%$ of carers will be invited to participate, generating a potential pool of 24 respondents. Thirteen days after the initial invitation is mailed out, a further proportion of carers will be invited. The exact number invited at round 2 will be judged based on initial uptake/opt-in to the study. The target sample size is 24 carers starting the package, with an expectation of 16 completing the package, allowing for withdrawal and loss to follow-up. The sample size is informed by pragmatic constraints, and since feasibility work is not driven by hypothesis testing, a sample size calculation is not required. ${ }^{61}$

Inclusion criteria:

I. Recognised as the main carer for a patient receiving specialist palliative care;

II. Supporting someone with nutrition/hydration and/or pain management needs;

III. Carer and patient are both aged over 18 years, and able to give informed consent;

IV. Proficient in English language;

V. Patient's life expectancy $>12$ weeks;

VI. The patient resides at home (not in residential aged care or receiving end-of-life care as an inpatient), though patient and carer do not have to live together;

VII. No formal diagnosis of major psychiatric disorder.

For both phases, carers will be sent invitation letters, requesting opt-in to the study within 2 weeks. The invitation letter will be sent from the hospice manager, who has no clinical or research role. Interested carers will be prompted to email or phone the research team indicating accepting or declining involvement. Written consent of carers will be gained at the start of the focus groups in phase 1. Phase 2 participants will provide initial verbal consent by calling the lead researcher to opt-in to the study. Subsequently, they will be sent a consent sheet for signing when baseline measures are taken. Multiple cycles of recruitment will be undertaken until the sample size is achieved.

Postintervention individual face-to-face interviews will be conducted with participants in phase 2 . If more than 16 carers remain involved in the study, then purposive sampling will be used, with interviewees stratified for degree of change. Participants who withdraw from the trial will not be approached to participate in interviews. Although their experience may shed useful light on the materials and trial processes, we anticipate that withdrawals will stem from increased complexity of the homecare situation and consequently that an interview would be unduly burdensome.

Participant timelines and flow through the study are illustrated in figure 2. Recruitment is pending (due to start in July 2016); enrolment will start in August 2016.

Since this is a small, psychosocial study and not a randomised study, comparators, sequence generation, allocation concealment, blinding, trial audit and data monitoring committee are not required.

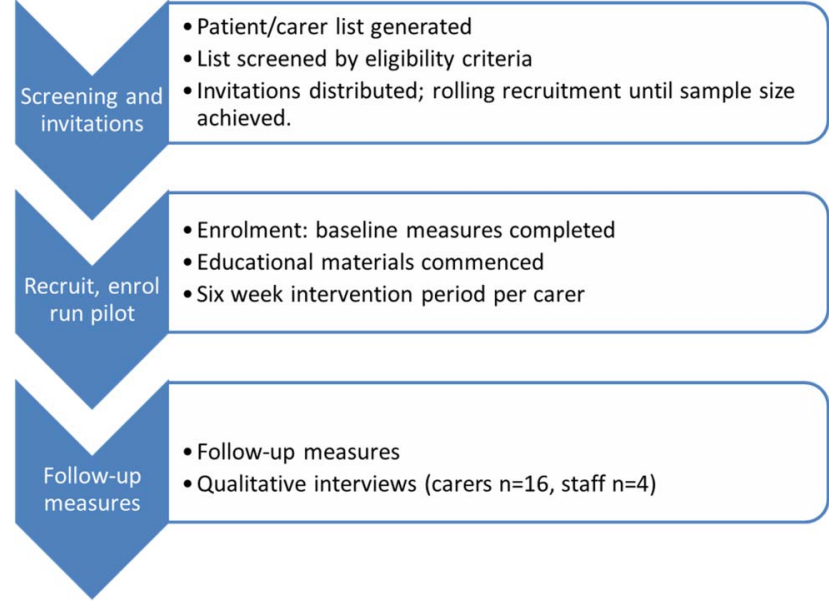

Figure 2 Carer flow through the study.

\section{Healthcare professional interviews}

Postintervention interviews will be conducted with key informant healthcare professionals $(n=4)$. Interviewees will be recruited from the specialist palliative care community team, following nomination by carers who will be asked to nominate the nurse or doctor most closely involved in providing care. These interviewees are likely to be nurses since this is the staff category most frequently engaged with patients and carers in the community.

\section{Data collection}

Data will be collected on the percentage of carers who meet the eligibility criteria set out above, and reasons for exclusion. Data on reasons for declining involvement will also be collated from participants where this information is proffered.

Outcome measures will be gathered at two time points (baseline preintervention and 6 weeks later) to evaluate the indicative effect of the intervention, and determine completion rates of the measures. The measures have been selected to prevent overburdening participants, by capping the length and number of measures used. We have generously estimated that all measures may take 30 min to complete but feel that many participants will complete them in $20 \mathrm{~min}$. These time estimates are based on consumer feedback which was sought when developing the package of outcome measures. The measures are self-complete and will be mailed to carers' homes with a prepaid envelope for return to the research team.

In order to assess the feasibility and acceptability of the intervention, carers will be asked complete adherence checklists, indicating which components of the education package were covered and in how much detail. This will be a simple checklist, with a three-point response (fully, some, none) for each section of the materials.

Qualitative interviews will be conducted with carers and healthcare staff to elicit appraisals of the 
intervention, and its success or otherwise. Participants will be asked about the most and least helpful elements of the educational materials, reasons for using the materials, how long they spent using them, whether parts were used multiple times, views on their willingness to participate if it were a randomised trial, the timing of the education, their use of the specialist palliative care service in answering any questions related to pain and nutrition/hydration, and whether anything could be changed or added to the educational materials.

Interviews with healthcare staff will elicit views on the acceptability and feasibility of the intervention; for example, eligibility criteria, method of recruitment, timing of offering the intervention in relation to the patient's trajectory, duration of intervention.

Researchers will be available to participants throughout the study period. A follow-up reminder phone call will be placed if outcome measures are not received within 2 weeks of distribution. All data proffered by carers on withdrawal, adverse effects or unintended consequences will be logged and reported.

Carer demographics will be collected including age, gender, education level, occupation, relationship to patient and patient diagnosis. Further patient-level data will not be sought.

\section{Outcome measures}

The primary outcome measure assesses self-efficacy. The secondary measures reflect an interest in assessing changes to carer outcomes more generally including self-report preparedness and competency. The outcome measures follow, where relevant, recently published European Association of Palliative Care White Paper reporting outcome measure use in palliative care. ${ }^{62}$

Primary outcome measure:

Self-efficacy will be measured using the Ugalde tool. ${ }^{63}$ This is a 21-item, 4-factor, self-report questionnaire which has been validated in cancer carers. The four factors are: resilience, self-maintenance, emotional connectivity and instrumental caregiving. Test-retest reliability and internal consistency were excellent (0.730.85 and $0.81-0.94$, respectively).

Secondary outcome measures:

- Cancer Caregiving Tasks, Consequences and Needs Questionnaire (CaTCoN). This is a 41-item scale to measure the extent of cancer caregiving tasks and consequences, and the caregivers' needs (mainly concerning information and communication received during contact with healthcare professionals). ${ }^{64}$

- The Preparedness for Caregiving Scale. ${ }^{65}$ This is an eight-item questionnaire that assesses how ready caregivers perceive they are for their role. Reliability was acceptable with Cronbach's $\alpha$ ranging from 0.86 to $0.92{ }^{66}$ Caregiver competence refers to the perceived adequacy of an individual's performance as a caregiver.

- A further bespoke questionnaire will capture core data on use (adherence) and feedback on the educational materials.

Recruitment and retention rates will be reported, and seek to be comparable to or exceed published rates in carer education studies using face-to-face delivery methods (see table 1 below). Consequently, this study aims to determine whether eligibility of around $43 \%$ and recruitment which equals or improves on $23-30 \%$ is achievable. Retention will be monitored, and compared against the wide-ranging experience of comparable studies.

\section{Analysis plan}

Collectively, data will be used to guide the refinement of the educational materials, and inform methodological parameters for a later scaled-up fully powered trial and provide an assessment of the feasibility and acceptability of the approach. Analysis of eligibility, and recruitment rates, will allow for national estimates to be calculated on number of potentially eligible carers across the country.

\begin{tabular}{|c|c|c|c|c|}
\hline Study & Eligibility & Recruitment & Retention & Confounders \\
\hline Hudson et $a l^{70}$ (2012) & $\begin{array}{l}43 \% \text { eligibility } \\
\text { (64 carers from } \\
149 \text { admissions) }\end{array}$ & $\begin{array}{l}23 \% \text { uptake } \\
\text { (15 of the } 64 \\
\text { eligible carers) }\end{array}$ & $\begin{array}{l}87 \% \text { (retained } 13 \text { of } \\
15 \text { carers) }\end{array}$ & $\begin{array}{l}\text { Involved carers of hospitalised } \\
\text { patients which may therefore } \\
\text { indicate a population with greater } \\
\text { time to participate than those } \\
\text { caring in their own homes }\end{array}$ \\
\hline Hudson et al ${ }^{11}$ (2008) & $\begin{array}{l}\text { Eligibility data not } \\
\text { stated }\end{array}$ & Not stated & $59 \%$ (retained 44 of 74 ) & $\begin{array}{l}\text { Required carers to attend a } \\
\text { palliative care service } 3 \text { times }\end{array}$ \\
\hline Hudson et al ${ }^{17}$ (2005) & $\begin{array}{l}\text { Eligibility data not } \\
\text { stated }\end{array}$ & $\begin{array}{l}30 \% \text { (106 of } 358 \\
\text { eligible carers) }\end{array}$ & $25 \%$ (27 of 106 retained) & $\begin{array}{l}3 \text { time points assessed, with } \\
\text { considerable loss to follow-up if } \\
\text { all } 3 \text { data points are required } \\
\text { ( } 45 / 106 \text { reduced to } 27 / 106)\end{array}$ \\
\hline Harding et $a l^{16}$ (2004) & $\begin{array}{l}\text { Eligibility data not } \\
\text { stated }\end{array}$ & $\begin{array}{l}25 \%(40 / 70 \\
\text { carers } \\
\text { approached })\end{array}$ & $\begin{array}{l}36 / 40 \text { retained in the } \\
\text { intervention group at T1 } \\
(90 \%) .24 \text { at T2 }(60 \%) \\
\text { and } 15 \text { at } \mathrm{T} 3(37.5 \%)\end{array}$ & 6 weekly sessions of $90 \mathrm{~min}$ \\
\hline
\end{tabular}


The focus group data (phase 1) will be used to generate and comment on the educational materials without being subjected to formal analysis.

As this is a feasibility and proof-of-concept study, formal power calculations and hypothesis testing are not appropriate, ${ }^{67}$ as the study is not designed to formally test for difference. Data from the primary and subsidiary outcome measures (phase 2) will be analysed using descriptive statistics, and if adequate data are generated, then basic inferential statistics (paired t-tests) will be used to identify statistically significant changes in outcomes. Multiple imputations will be used if required. These data will be used to inform power calculations for a later fully powered trial. Intention-to-treat analysis will be used. Since this study is a single-armed trial, recruitment estimates will be calculated cautiously, informed both by enrolment in phase 2 and qualitative interview data on recruitment processes in phase 2.

Baseline demographic characteristics will be reported as mean and SD for continuous data and number (percentage) for categorical data. Analysis of the adherence checklist data will proceed using frequency counts to identify elements of the educational materials which are most and least frequently used.

Qualitative interview data from phase 2 will be digitally recorded, transcribed and managed using NVivo (V.10) software. The data will be analysed thematically. ${ }^{68}$ Analysis will proceed through a five-stage process of familiarisation, identifying a thematic framework, indexing the data, synthesising across respondents and data interpretation to form key themes. Analysis will be conducted by the chief investigator (a psychooncology researcher), nurse researchers and a social science research assistant. Carer and health professional data will be analysed separately and then synthesised to identify overlapping, complementary and discordant themes, both of which will be reported. Data analysis will focus on identifying features of acceptability and feasibility of the intervention and provide in-depth understanding of the content of the educational material, and trial processes such as the timing of provision of the resources.

Members of the research team will have access to the cleaned data set.

\section{ETHICS AND DISSEMINATION}

Any required protocol amendments will be submitted to the Calvary Health Care Ethics Committee. The trial is registered with the Australian New Zealand Clinical Trials Group. All study participants will be asked to provide written consent. Data will be held in locked cabinets and password-protected electronic files. All identifying details will be removed, and replaced with alphanumeric identifiers. Data in paper form will be stored in a locked cabinet in a locked office and destroyed after 5 years. Computerised data will be stored in a password-protected file, destroyed after 5 years. No public access to the data is planned.
Criteria for discontinuing the trial for an individual relate to stated carer burden, or death of the person they are caring for. Carers will self-define burden and consequently decide themselves if they wish to continue. Death of the patient will trigger contact from the research team to offer condolences; the educational package may be retained by the carer or returned depending on their preference. Adverse events will be reported to the ethics committees.

The study was designed with input from former caregivers, who advised on the study design and initial topics to designed and delivered. Carers who are enrolled into the study are covered by indemnity for negligent harm through insurance provided by the study sponsor. Ancillary care will be provided by the hospital, including psychosocial support and pastoral care. Should the study indicate feasibility and acceptability, then a further fully powered trial will be planned to evidence efficacy and findings shared with clinicians, carers and patients through accessible summaries of the study results.

Data entry and coding will be conducted by one research assistant with a sample of $20 \%$ checked for accuracy by a second researcher. Security and storage of data will be managed by the principle investigator.

Results will be published in peer-reviewed journals, presented at conferences and a lay summary sent to participants. Authorship will be allocated using the guidelines for authorship defined by the International Committee of Medical Journal Editors.

\section{Steering committee}

The study has an international steering committee comprising experts in palliative care education, and distance learning for carers of people with dementia, and national lead bodies for carers (Carers Australia) and palliative care (Palliative Care Australia).

\section{DISCUSSION}

This study centralises the need to address the informational needs of informal carers in palliative care community settings. It tests whether a distance-learning approach can address the difficulties of supporting carers to feel supported in their role which have been highlighted in the literature. ${ }^{469}$ The longer term aims of this work are to inform a national efficacy trial, of distancelearning approaches to supporting carers to develop and apply caring knowledge and skills, for those unable to attend education sessions in person. If the findings indicate that the concept and approach is acceptable to carers, further modules could be developed, for example, preparing for death/dying, and additional modules for carers of patients with non-malignant conditions.

The proof-of-concept trial will not measure the distal impact of the education on patients through more competent and supported carers, evidenced by reduced patient symptomatology, nor on the patient/carer relationship, which is likely also to be impacted by greater self-efficacy of the carer. 
Author affiliations

${ }^{1}$ Calvary Centre for Palliative Care Research, Australian Catholic University and Calvary Health Care Bruce, Canberra, Australian Capital Territory, Australia ${ }^{2}$ St Columba's Hospice and Queen Margaret University, Edinburgh, UK ${ }^{3}$ University at Buffalo School of Nursing, Buffalo, New York, USA

${ }^{4}$ Nell Hodgson Woodruff School of Nursing, Emory University, Atlanta, Georgia, USA

Twitter Follow Liz Forbat at @lizforbat

Contributors LF led the design and conception of the study, with contributions from $\mathrm{EH}, \mathrm{KH}$ and ML. LF wrote the first draft of the manuscript, and $\mathrm{LF}, \mathrm{EH}, \mathrm{ML}$ and $\mathrm{KH}$ revised it critically for important intellectual content. $\mathrm{LF}, \mathrm{EH}, \mathrm{ML}$ and $\mathrm{KH}$ have given final approval of the version to be published. $\mathrm{LF}, \mathrm{EH}, \mathrm{ML}$ and $\mathrm{KH}$ have participated sufficiently in the work to take public responsibility for appropriate portions of the content; and agree to be accountable for all aspects of the work in ensuring that questions related to the accuracy or integrity of any part of the work are appropriately investigated and resolved. LF was involved in resolving scientific and public queries.

Funding The study is funded by Australian Capital Territory (ACT) Health. The study sponsor is Australian Catholic University.

Competing interests None declared.

Ethics approval Ethical approval has been provided by the participating site, Calvary Health Care, Canberra, reference 02-2016, and the Australian Catholic University.

Provenance and peer review Not commissioned; externally peer reviewed.

Data sharing statement Data emerging from the study may be accessed by emailing the corresponding author. This may be subject to further ethical review requirements.

Open Access This is an Open Access article distributed in accordance with the Creative Commons Attribution Non Commercial (CC BY-NC 4.0) license, which permits others to distribute, remix, adapt, build upon this work noncommercially, and license their derivative works on different terms, provided the original work is properly cited and the use is non-commercial. See: http:// creativecommons.org/licenses/by-nc/4.0/

\section{REFERENCES}

1. World Health Organization (WHO). National cancer control programmes: policies and managerial guidelines. Geneva: WHO, 2002.

2. Hudson P. Improving support for family carers: key implications for research, policy and practice. Palliat Med 2013;27:581-2.

3. Andershed B, Ternestedt BM. Development of a theoretica framework describing relatives' involvement in palliative care. J Adv Nurs 2001;34:554-62.

4. Harrop E, Byrne A, Nelson A. "It's alright to ask for help": findings from a qualitative study exploring the information and support needs of family carers at the end of life. BMC Palliat Care 2014;13:22.

5. Morris SM, King C, Turner M, et al. Family carers providing support to a person dying in the home setting: a narrative literature review. Palliat Med 2015;29:487-95.

6. Ventura AD, Burney S, Brooker J, et al. Home-based palliative care: a systematic literature review of the self-reported unmet needs of patients and carers. Palliat Med 2014;28:391-402.

7. Reid J. Psychosocial, educational and communicative interventions for patients with cachexia and their family carers. Curr Opin Support Palliat Care 2014;8:334-8.

8. Bee PE, Barnes P, Lucker K. A systematic review of informal caregivers' needs in providing home-based end-of-life care to people with cancer. J Clin Nurs 2009;18:1379-93.

9. Latter S, Hopkinson J, Lowson E, et al. Study protocol for a feasibility trial of Cancer Carer Medicines Management (CCMM): an educational intervention for carer management of pain medication in cancer patients at end of life. Working Papers Health $\mathrm{Sci}$ 2013:1:1-7.

10. Simons G, Thompson SB, Smith Pasqualini MC. An innovative education programme for people with Parkinson's disease and their carers. Parkinsonism Relat Disord 2006;12:478-85.

11. Hudson $P$, Quinn K, Kristjanson L, et al. Evaluation of a psycho-educational group programme for family caregivers in home-based palliative care. Palliat Med 2008;22:270-80.
12. Hopkinson JB, Brown JC, Okamoto I, et al. The effectiveness of patient-family carer (couple) intervention for the management of symptoms and other health-related problems in people affected by cancer: a systematic literature search and narrative review. J Pain Symptom Manage 2012;43:111-42.

13. Hepburn K, Lewis M, Wexler Sherman C, et al. The Savvy caregiver program: developing and testing a transportable dementia family caregiver training program. Gerontologist 2003;43:908-1115.

14. Holm M, Arestedt K, Carlander I, et al. Short-term and long-term effects of a psycho-educational group intervention for family caregivers in palliative home care-results from a randomized control trial. Psychooncology 2016;25:795-802.

15. Harding R, Higginson IJ. What is the best way to help caregivers in cancer and palliative care? A systematic literature review of interventions and their effectiveness. Palliat Med 2003;17:63-74.

16. Harding R, Higginson IJ, Leam C, et al. Evaluation of a short-term group intervention for informal carers of patients attending a home palliative care service. J Pain Symptom Manage 2004;27:396-408.

17. Hudson P, Aranda S, Hayman-White K. A psycho-educational intervention for family caregivers of patients receiving palliative care: a randomized controlled trial. J Pain Symptom Manage 2005;30:329-40.

18. Thomas $\mathrm{K}$, Moore $\mathrm{G}$. The development and evaluation of a multimedia resource for family carers of patients receiving palliative care: a consumer-led project. Palliat Support Care 2015;13:417-23.

19. Griffith PC, Whitney KM, Kovaleva M, et al. Development and implementation of tele-savvy for dementia caregivers: a department of veterans affairs clinical demonstration project. Gerontologist 2016;56:145-54.

20. Lewis M, Hepburn K. Internet-based program for dementia caregivers. Am J Alzheimers Dis Other Demen 2010;25:674-9.

21. Oldham L, Kristjanson L. Development of a pain management programme for family carers of advanced cancer patients. Int J Palliat Nurs 2004;10:91-9.

22. Du S, Liu Z, Liu S, et al. Web-based distance learning for nurse education: a systematic review. Int Nurs Rev 2013;60:167-77.

23. Smith PJ, Wigmore SJ, Paisley A, et al. Distance learning improves attainment of professional milestones in the early years of surgical training. Ann Surg 2013;258:838-42; discussion 42-3.

24. Doyle NW, Jacobs K. Accommodating student learning styles and preferences in an online occupational therapy course. Work 2013;44:247-53.

25. Hattink B, Meiland $F$, van der Roest $\mathrm{H}$, et al. Web-based STAR E-learning course increases empathy and understanding in dementia caregivers: results from a randomized controlled trial in the Netherlands and the United Kingdom. J Med Internet Res 2015;17:e241.

26. Gant JR, Steffen AM, Lauderdale SA. Comparative outcomes of two distance-based interventions for male caregivers of family members with dementia. Am J Alzheimers Dis Other Demen 2007;22: $120-8$

27. Lovett S, Gallagher D. Psychoeducational interventions for family caregivers: preliminary efficacy data. Behav Ther 1988;19:321-30.

28. Hudson P. A conceptual model and key variables for guiding supportive interventions for family caregivers of people receiving palliative care. Palliat Support Care 2003;1:353-65.

29. Bandura A. Self-efficacy: toward a unifying theory of behavioral change. Psychol Rev 1977;84:191-215.

30. Zeiss A, Gallagher-Thompson D, Lovett S. Self-efficacy as a mediator of caregiver coping: development and testing of an assessment model. J Clin Geropsychol 1999;5:221-30.

31. Mystakidou K, Parpa E, Panagiotou I, et al. Caregivers' anxiety and self-efficacy in palliative care. Eur J Cancer Care 2013;22:188-95.

32. Campbell M, Fitzpatrick R, Haines $A$, et al. Framework for design and evaluation of complex interventions to improve health. BMJ 2000;321:694-6.

33. Craig P, Dieppe P, Macintyre S, et al. Developing and evaluating complex interventions: the new medical research council guidance. BMJ 2008;337:a1655.

34. Pawson R, Tilley N. Realistic evaluation. London: Sage, 1997.

35. Armes PJ, Addington-Hall J. Perspectives on symptom control in patients receiving community palliative care. Palliat Med 2003;17:608-15.

36. Docherty A, Owens A, Asadi-Lari M, et al. Knowledge and information needs of informal caregivers in palliative care: a qualitative systematic review. Palliat Med 2008;22:153-71.

37. Letizia M, Creech S, Norton E, et al. Barriers to caregiver administration of pain medication in hospice care. Int $\mathrm{J}$ Older People Nurs 2004;27:114-24.

38. Lin CC. Barriers to the analgesic management of cancer pain: a comparison of attitudes of Taiwanese patients and their family caregivers. Pain 2000;88:7-14. 
39. Mehta A, Chan LS, Cohen SR. Flying blind: sources of distress for family caregivers of palliative cancer patients managing pain at home. J Psychosoc Oncol 2014;32:94-111.

40. McClement SE, Harlos M. When advanced cancer patients won't eat: family responses. Int J Palliat Nurs 2008;14:182-8.

41. Cohen MZ, Torres-Vigil I, Burbach BE, et al. The meaning of parenteral hydration to family caregivers and patients with advanced cancer receiving hospice care. J Pain Symptom Manage 2012;43:855-65.

42. Chai HZ, Krishna LK, Wong VH. Feeding: what it means to patients and caregivers and how these views influence Singaporean Chinese caregivers' decisions to continue feeding at the end of life. $A m$ J Hosp Palliat Care 2014;31:166-71.

43. Funk L, Stajduhar K, Toye C, et al. Part 2: home-based family caregiving at the end of life: a comprehensive review of published qualitative research (1998-2008). Palliat Med 2010;24:594-607.

44. Henderson J, Forbat L. Relationship-based social policy: personal and policy constructions of care. Crit Soc Policy 2002;22:669-87.

45. Wittenberg E, Goldsmith J, Ferrell B, et al. Promoting improved family caregiver health literacy: evaluation of caregiver communication resources. Psychooncology 2016. doi:10.1002/ pon.4117 [Epub ahead of print 16 Mar 2016]

46. Cooley ME, Moriarty H, Berger MS, et al. Patient literacy and the readability of written cancer educational materials. Oncol Nurs Forum 1995;22:1345-51.

47. Moore MG. The theory of transactional distance. In: Moore MG, ed. Handbook of distance education. 2nd edn. Mahwah, NJ: Lawrence Erlbaum, 2007:89-105.

48. Kim Y, Thayne J. Effects of learner-instructor relationship-building strategies in online video instruction. Distance Educ 2015;36:100-14.

49. Sakiz G. Perceived instructor affective support in relation to academic emotions and motivation in college. Educ Psychol 2012;32:63-79.

50. Andrade MS, Bunker EL. A model for self-regulated distance language learning. Distance Educ 2009;30:47-61.

51. Ausburn L. Course design elements most valued by adult learners in blended online education environments: an American perspective. Educ Media 2004;41:327-37.

52. Cropley AJ, Thomas TN. Distance education and distance learning: some psychological considerations. Distance Educ 1983;4:27-39.

53. Hough M. Motivation of adults: implications of adult learning theories for distance education. Distance Educ 1984;5:7-23.

54. Dolmans D, Gijbels D. Research on problem-based learning: future challenges. Med Educ 2013;47:214-18.

55. Harding R, Higginson I. Working with ambivalence: informal caregivers of patients at the end of life. Support Care Cancer 2001;9:642-5.
56. McAllister L, Lincoln M, McLeoid S, et al. Facilitating learning in clinical settings. Cheltenham: Stanley Thornes, 1997.

57. Cornelius S, Gordon C, Ackland A. Towards flexible learning for adult learners in professional contexts: an activity-focused course design. Interact Learn Environ 2011;19:381-93.

58. Ramirez A, Addington-Hall J, Richards M. ABC of palliative care. The carers. BMJ 1998;316:208-11.

59. Del Rio MI, Shand B, Bonati $\mathrm{P}$, et al. Hydration and nutrition at the end of life: a systematic review of emotional impact, perceptions, and decision-making among patients, family, and health care staff. Psychooncology 2012;21:913-21.

60. Bentley B, O'Connor M. Conducting research interviews with bereaved family carers: when do we ask? J Palliat Med 2015;18:241-5.

61. Billingham SA, Whitehead AL, Julious SA. An audit of sample sizes for pilot and feasibility trials being undertaken in the United Kingdom registered in the United Kingdom Clinical Research Network database. BMC Med Res Methodol 2013;13:104.

62. Bausewein C, Daveson BA, Currow DC, et al. EAPC White Paper on outcome measurement in palliative care: improving practice, attaining outcomes and delivering quality servicesrecommendations from the European Association for Palliative Care (EAPC) Task Force on Outcome Measurement. Palliat Med 2016;30:6-22.

63. Ugalde A, Krishnasamy M, Schofield P. Development of an instrument to measure self-efficacy in caregivers of people with advanced cancer. Psychooncology 2013;22:1428-34.

64. Lund L, Ross L, Groenvold M. The initial development of the 'Cancer Caregiving Tasks, Consequences and Needs Questionnaire' (CaTCoN). Acta Oncol 2012;51:1009-19.

65. Archbold PG, Stewart BJ, Greenlick MR, et al. Mutuality and preparedness as predictors of role strain. Res Nurs Health 1990;13:375-84.

66. Archbold P, Stewart B. Scale summary: preparedness for caregiving Portland: Oregon Health Sciences University, 1993.

67. Arain M, Campbell MJ, Cooper CL, et al. What is a pilot or feasibility study? A review of current practice and editorial policy. BMC Med Res Methodol 2010;10:67.

68. Braun V, Clarke V. Using thematic analysis in psychology. Qual Res Psychol 2006;3:77.

69. Ewing G, Grande G. Development of a Carer Support Needs Assessment Tool (CSNAT) for end-of-life care practice at home: a qualitative study. Palliat Med 2013;27:244-56.

70. Hudson PL, Lobb EA, Thomas K, et al. Psycho-educational group intervention for family caregivers of hospitalized palliative care patients: pilot study. J Palliat Med 2012;15:277-81. 